\title{
Distributed resource scheduling in smart grid with electric vehicle deployment using fireworks algorithm
}

\author{
K. Srikanth REDDY ${ }^{1}$, Lokesh Kumar PANWAR ${ }^{2}$, Rajesh KUMAR ${ }^{2}$, \\ Bijaya Ketan PANIGRAHI ${ }^{1}$
}

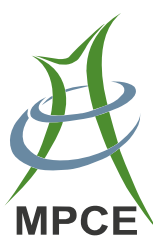

\begin{abstract}
Global warming and climate change are two key probing issues in the present context. The electricity sector and transportation sector are two principle entities propelling both these issues. Emissions from these two sectors can be offset by switching to greener ways of transportation through the electric vehicle (EV) and renewable energy technologies (RET). Thus, effective scheduling of both resources holds the key to sustainable practice. This paper presents a scheduling scenario-based approach in the smart grid. Problem formulation with dual objective function including both emissions and cost is developed for conventional unit commitment with EV and RET deployment. In this work, the scheduling and commitment problem is solved using the fireworks algorithm which mimics explosion of fireworks in the sky to define search space and the distance between associated sparks to evaluate global minimum. Further, binary coded fireworks algorithm is developed for the proposed scheduling problem in the smart grid. Thereafter, possible scenarios in
\end{abstract}

CrossCheck date: 27 January 2016

Received: 12 March 2015/Accepted: 28 September 2015/Published online: 25 March 2016

(C) The Author(s) 2016. This article is published with open access at Springerlink.com

$\triangle$ Rajesh KUMAR

rkumar.ee@gmail.com

K. Srikanth REDDY

srikanthkonda.eee@gmail.com

Lokesh Kumar PANWAR

lokesh.panwar28@gmail.com

Bijaya Ketan PANIGRAHI

bkpanigrahi@ee.iitd.ac.in

1 IIT Delhi, New Delhi, India

2 MNIT Jaipur, Jaipur, Rajasthan, India conventional as well as smart grid are put forward. Following that, the proposed methodology is simulated using a test system with thermal generators.

Keywords Unit commitment problem (UCP), Binary fireworks algorithm (BFWA), Constrained optimization, Renewable energy technologies (RETs), Plug-in electric vehicle (PEV)

\section{Introduction}

With the overwhelming importance that sustainability has gained in recent time, it is vital for the significant entities of global emissions like transportation and power generation to abridge their emissions keeping in mind the end goal to cut down them to $80 \%$ by 2050 [1], thereby accomplishing the goals set in endorsing Kyoto Protocol launched by United Nations Framework Convention on Climate Change (UNFCCC) [2]. Subsequently, the transportation and electricity sectors have committed to promoting green alternatives by exploiting the potential benefits of nonconventional, renewable and electric vehicle resources in every possible direction for a sustainable future.

Electric power utilities around the globe witnessing whole modernization and rebuilding lately, because of the developing smart grid innovations [3]. One of the real strengths driving this pattern is the combination of renewable energy technologies (RET) into power generation. Unit commitment (UC) is a traditional problem in the electric network which empowers effective asset planning at least cost, yet fulfilling all the network and system constraints [4]. Renewable energy joining with the current customary fossil fuel plants has prompted revolutions in the power sector [5] in heading towards sustainable development. Wind energy asset with high penetration was planned along thermal units 
to cut down emissions [6]. Lately, backed by the cost effective manufacturing process and fiscal policy implications around the world, solar photovoltaic energy was also considered on short-term scheduling basis [7]. Because of the way that renewable energy brings in instability into the framework, it is essential to consider the reliability before incorporating them into the framework. In the UCP with strict limitations like load fulfilment and other reliability issues (system reserve, stability and regulation, etc.) handling the uncertainty through either accurate forecasting methods or suppressing the variability by employing storage technologies is a key prospect [8].

As a result of electrification of the transportation sector, the stress on the existing electric network is likely to change with charging demands of the plug-in electric vehicles (PEV) [9]. However, intelligent handling of the PEVs in conjunction with the utility resources like thermal units and RETs can minimize the cost and burden of the network [10]. In addition, the coordination of RETs with PEVs in which part or entire PEV charging load is supplied by RET has been in practice to reduce network congestion, cost and emissions into environment [11].

Over the past decade, various optimization techniques have been proposed by various researchers to solve the UCP. Techniques like branch and bound method (BBM), dynamic programming (DP), priority list (PL), mixed integer linear programming (MILP) and Lagrangian relaxation (LR) algorithms are developed to solve the UCP. On the other hand, each methodology has its qualities and confinements. Among these optimization techniques, PL offers straightforwardness and slightest computational time, however a tradeoff must be made with the solution quality [12]. With DP, absence of adaptability and expanded calculation time at higher measurement ends up being the disadvantageous in executing UCP for wide range, large number of thermal units [13]. While, exponentially aggravating computational time system dimension hampers the use of MILP and BBM techniques for UCP in large systems [14]. Finally, when executed with LR, UCP being a non-convex optimization technique, prompts troubles in determination of feasible global solution [15].

Lately, heuristic optimization approaches became extremely well known because of their effortlessness and proficiency in global minimum search. In the past studies, genetic algorithm (GA) is developed by observing the processes of reproduction, natural selection and mutation in animals and utilized to tackle UCP [16]. Additionally, hybrid variations with combinations of different algorithms like LRGA are devised to reduce the search space thereby making the search for optimal search effective [17]. Thereupon, inspired by swarm intelligence like social behavior and coordination principles, particle swarm optimization (PSO) is proposed and developed to improve the quality of UCP solution [18].
Further, to allocate ON/OFF status of thermal units distinctive varieties of PSO like binary particle swarm optimization (BPSO), quadratic binary particle swarm optimization (QBPSO), improved binary particle swarm optimization (IBPSO) is proposed for UCP [19-21]. Afterwards, algorithms like ant colony optimization (ACO) deduced from the natural behavior of ants in discovering the shortest path looking for food, are exploited in successful handling of commitment and scheduling of thermal units to minimize the generation cost [22].

Recently, by mimicking particular behavior of firework display in the sky, fireworks algorithm (FWA) is proposed [23]. In this algorithm, fireworks are comprehensively partitioned into two sorts, good and bad fireworks in view of the explosion and associated sparkles. The firework explosion with good cluster giving a spectacular display is characterized as a good firework and vice versa. The basic idea behind the fireworks assumes the area spread by the sparks associated with a firework explosion represents the search space. Therefore, a good firework with closely associated sparks all around symbolizes an effective search space with a higher probability of optimal solution, and a bad firework with distant sparks in the larger area represents ineffective search space. Hence, on observing the better performance of FWA over other existing techniques regarding convergence and optimal search for benchmark problems, authors would like to expand its application to complex optimization problem like UCP through a binary variant of FWA.

\section{Problem formulation}

The UCP is an optimization problem in which for the given load and available generation units, the total operational cost is minimized by intelligent commitment and optimal power allocation under specified network and unit constraints. In this paper, short-term power scheduling of thermal units is carried out for 24 hours. The operational cost includes fuel and startup costs, also, incorporates system constraints like load balance, reserve and units constraints like up/down ramp rates, times, generation limits etc.

\subsection{Model development}

\subsubsection{Wind energy generator (WEG)}

Variable nature of wind resource complicates the scheduling of wind energy. However, accurate prediction of wind resource and appropriate modeling can improve its accuracy [24]. In literature, there are several models postulated for wind energy generation with most appropriate one being formulation of wind energy from power curve (Fig. 1) of wind turbine [25]. 


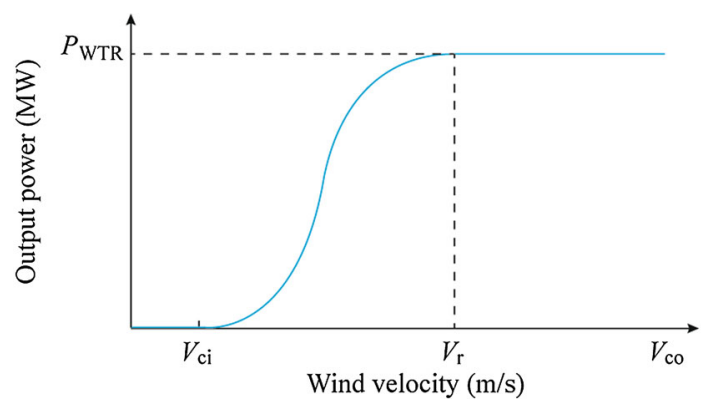

Fig. 1 Power curve of wind energy generator

Modern wind turbines are modeled to operate in four modes namely, below cut in, linear, rated and cut-out speeds as formulated below:

$P_{\mathrm{weg}}(t)=\left\{\begin{array}{lll}0 & \text { if } & V(t)<V_{\mathrm{ci}} ; \quad V_{\mathrm{co}}<V(t) \\ \Psi(t) & \text { if } & V_{\mathrm{ci}}<V(t)<V_{\mathrm{r}} \\ P_{\mathrm{wtr}} & \text { if } & V_{\mathrm{r}}<V(t)<V_{\mathrm{co}}\end{array}\right.$

where $V_{\mathrm{ci}}, V_{\mathrm{r}}, V_{\mathrm{co}}$ denote cut-in, rated and cut out speeds of wind turbine respectively which are characteristic of particular wind turbine under study and $\Psi(t)$ is the output power of wind turbine operating in linear region which is given by:

$\Psi(t)=x V(t)^{2}+y V(t)+z$

In above equation, coefficients $x, y$ and $z$ are turbine specific.

\subsubsection{Solar photovoltaic generation (SPV)}

The power output of photovoltaic generator can be found as a function of global solar irradiance and cell temperature using the following equation [26]:

$P_{\mathrm{pev}}(t)=\frac{G}{G_{\mathrm{r}}} P_{\mathrm{m}}\left\{1+\lambda\left(T-T_{\mathrm{r}}\right)\right\}$

where $G$ is the global irradiance; $P_{\mathrm{m}}$ the maximum power under standard testing conditions (STC); $T$ the cell temperature; $T_{\mathrm{r}}$ the temperature at STC $\left(25^{\circ} \mathrm{C}\right) ; G_{\mathrm{r}}$ the global irradiance at STC $\left(1000 \mathrm{~W} / \mathrm{m}^{2}\right)$; and $\lambda$ the maximum power correction for temperature [27].

\subsection{Dual objective function}

Managing all type of load and distributed generation is a critical exercise. In this paper, RET and PEV are used to reduce emissions from electricity and transportation sectors. Optimization problem is a dual objective function consisting of cost and emissions:

$F(P)=\Phi_{1} T C+\Phi_{2} T E$

where $T C$ and $T E$ are the total operational cost, total emissions respectively; and $\phi_{1}, \phi_{2}$ are the weight factors. The total operational cost (TC) is given by:
$T C=\sum_{t=1}^{T} \sum_{i=1}^{N G}[\{C(P(i, t)) A(i, t)\}]+\{S C(i, t) A(i, t)\}$

where $A(i, t)$ is the binary variable representing the ONOFF status of thermal unit $i$ in hour $t$; and $C(P(i, t))$ is the fuel cost function of $i^{\text {th }}$ thermal unit for $t^{\text {th }}$ hour which is given by:

$C(P(i, t))=a_{i} P(i, t)^{2}+b_{i} P(i, t)+c_{i}$

where $a^{i}, b^{i}$ and $c^{i}$ are the fuel cost coefficients of $i^{\text {th }}$ thermal unit. For thermal units, hot start-up cost $H S C(i)$ or cold start-up costs $C S C(i)$ will be accounted depending upon the boiler operating characteristics as follows:

$S C(i, t)=\left\{\begin{array}{l}H S C(i), \operatorname{MDT}(i) \leq O F F h(i) \leq C S h(i)+\operatorname{MDT}(i) \\ C S C(i), C S h(i)+\operatorname{MDT}(i) \leq O F F h(i)\end{array}\right.$

where $\operatorname{MDT}(i), C S h(i)$ are the minimum down time (in hours), cold start hours of $i^{\text {th }}$ thermal unit and $O F F h(i)$ is the time in hours for which ith unit is in OFF state. The total emission cost is given by:

$T E=E_{c}(P(i, t))=\theta_{i}\left(\chi_{i} P(i, t)^{2}+\beta_{i} P(i, t)+\gamma_{i}\right)$

where $\theta_{i}$ (\$/ton) is the emission penalty cost of $i^{\text {th }}$ thermal unit given as:

$\theta_{i}=\frac{a_{i} P_{i, \max }^{2}+b_{i} P_{i, \max }+c_{i}}{\chi_{i} P_{i, \max }^{2}+\beta_{i} P_{i, \max }+\gamma_{i}}$

In order to evaluate the overall effectiveness of PEV, emissions resulting from conventional vehicle are also considered for comparison [28]. The emissions are modeled as linear approximate model given by:

$\xi\left(T_{l}, \varepsilon_{i}\right)=T_{l} \cdot \varepsilon_{i}$

where $\xi()$ is the linear approximate function; $T_{l}$ the transit length; and $\varepsilon_{i}$ the emission coefficient expressed in terms of ton/mile travelled.

\subsection{System constraints}

\subsubsection{Load balance constraint}

At every point of time, the load and generation should be strictly balanced in order to assure the system frequency requirements. The total generation i.e., power dispatched from thermal units, distributed generators and PEVs has to satisfy the total system load for the hour.

$\sum_{t=1}^{T} \sum_{i=1}^{N G} P(i, t)+P_{\mathrm{spv}}(t)+P_{\mathrm{weg}}(t)+P_{\mathrm{pev}}(t)=P l(t)$

where 
$P_{\mathrm{pev}}(t)= \begin{cases}+P_{\mathrm{pev}}(t) & \text { for discharging } \\ -P_{\mathrm{pev}}(t) & \text { for charging } \\ 0 & \text { when EV is in transit }\end{cases}$

To avoid power loss of the PEV battery during chargedischarge operations, maximum charging and discharging limits are enforced as given by,

$P_{\text {pev }}^{\text {min }}<P_{\text {pev }}(t)<P_{\text {pev }}^{\text {min }}$

where $P_{\mathrm{pev}}^{\mathrm{min}}$ is the maximum discharge level, and $P_{\mathrm{pev}}^{\min }$ is the maximum charge limit of PEV.

\subsubsection{Reserve constraint}

The electrical system is guarded by reserve in case of contingency occurrence and generation outage as given by:

$\sum_{t=1}^{T} \sum_{i=1}^{N G} G R(i, t) A(i, t)+P_{\mathrm{spv}}(t)+P_{\mathrm{weg}}(t)+P_{\mathrm{pev}}(t) \geq R R(t)$

where $R R(t)$ is the required reserve for $t^{\text {th }}$ hour given as a percentage change in load/generation due to of probability occurrence (r)

$R R(t)=P l(t) \cdot(1+r)$

and $G R(i, t)$ is the reserve available from $i^{\text {th }}$ thermal unit at $t^{\text {th }}$ hour which is given by,

$G R(i, t)=\left(P_{i, \max }-P(i, t)\right) A(i, t)$

where $P_{i, \max }$ corresponds to the maximum capacity of $i^{\text {th }}$ thermal unit.

\subsection{Thermal unit constraints}

\subsubsection{Generation limits/bounds}

For every instant of time, thermal unit generation will be constricted by upper and lower generation limits as given by

$P_{i, \max } \leq P(i, t) \leq P_{i, \max }$

where $P_{i, \min }, P_{i, \max }$ are the minimum and maximum generation limits of $i^{\text {th }}$ thermal unit respectively.

\subsubsection{Minimum up/down times}

There exists a predefined time between ON/OFF exchanging operations of a generation unit because of the thermal and mechanical limits forced by boiler operational attributes.

$\begin{cases}(1-A(i, t+1)) \operatorname{MUT}(i, t) \leq \operatorname{ONh}(t), & \text { if } \quad A(i, t)=1 \\ A(i, t+1) \operatorname{MDT}(i, t) \leq \operatorname{OFFh}(i), & \text { if } \quad A(i, t)=0\end{cases}$ where $\operatorname{MUT}(i, t)$ the minimum time for which the unit ought to be continued once it is committed; and $O N h(i)$ is the number of hours from which the $i^{\text {th }}$ unit is in on state and binary digits 1,0 stands for ON, OFF conditions of a thermal unit.

\subsubsection{Ramp up/down rates}

Considering the physical limitations in changing the generation output of a turbine ramp up/down rates are introduced at each hour in the UC problem as given by:

$P_{i}^{\min }(t) \leq P(i, t) \leq P_{i}^{\max }(t)$

where

$\left\{\begin{array}{l}P_{i}^{\min }(t)=\max \left(\left(P_{i}^{\min }\right), P(i, t-1)-R D_{i}\right) \\ P_{i}^{\max }(t)=\min \left(\left(P_{i}^{\max }\right), P(i, t-1)-R U_{i}\right)\end{array}\right.$

where $R D_{i}, R U_{i}$ are ramp down and up rates of $i^{\text {th }}$ generator respectively; and $P(i, t-1)$ is the power generation of $i^{\text {th }}$ plant during $(t-1)^{\text {th }}$ hour.

\subsubsection{Initial states}

At the point when committing the units for the following 24 hours the status of units at the most recent hour of earlier day must be inspected as they are prone to influence start-up costs and minimum up/down times.

\section{Algorithm development}

\subsection{FWA overview}

The optimal solution search using the FWA algorithm is a sequential process in which the explosion of the firework is followed by selection of sparks for the next explosion based on the number and distance between sparks associated with the firework explosion. The good firework selected for next round of explosion denotes the feasible optimal location of the optimization problem in the search space defined. The characteristics of the FWA which aid in selection of sparks for the next generation are given below.

\subsubsection{Number of sparks}

For the objective function $f(x)$, variables $x(1), x(2), \cdots$, $x(i)$ denotes the number of fireworks and the number of sparks generated by $i^{\text {th }}$ fireworks is given by

$S_{i}=m \frac{y_{\max }-f\left(x_{i}\right)+\xi}{\sum_{i=1}^{n}\left(y_{\max }-f\left(x_{i}\right)\right)+\zeta}$

where the number of created sparks from $n$ firecrackers is 
controlled by parameter $m, y_{\max }$ indicates the most worst value of objective function $\max \left(f\left(x_{i}\right)\right)$ acquired for $\mathrm{n}$ fireworks i.e., $(i=1,2, \cdots, n)$ and the smallest constant $\xi$ is utilized to avoid the event of zero-division-error. In order to avoid devastating effects of glorious fireworks, $S_{i}$ is bounded as given by

$\hat{S}_{i}= \begin{cases}S_{\max ^{\prime}} & \text { if } S_{i}>S_{\max } \\ S_{\min ^{\prime}} & \text { if } S_{i}>S_{\max } \\ \operatorname{round}\left(S_{i}\right), & \text { otherwise }\end{cases}$

\subsubsection{Amplitude of explosion}

The amplitude of the firework is inversely proportional to the spark number such that, a good firework with large number of sparks will have small amplitude and vice versa.

$A_{i}=\hat{A} \frac{f\left(x_{i}\right)-y_{\min }+\xi}{\sum_{i=1}^{n}\left(f\left(x_{i}\right)-y_{\min }\right)+\xi}$

where $\hat{A}$ is the maximum amplitude of explosion; and $y_{\min }$ is the minimum value of objective function min $(f(x))$ obtained for fireworks $(i=1,2, \cdots, n)$.

\subsubsection{Generation of sparks}

During the explosion process, $\mathrm{z}$ random directions can affect the sparks associated with the explosion and the number of random directions is given by

$z=\operatorname{round}(d \cdot \operatorname{rand}(0,1))$

where $d$ is the $x$ location's dimensionality and rand $(0,1)$ corresponds to uniform distribution with in $\{0,1\}$. Algorithm development and implementation for the same is depicted in Algorithm 1.

\section{Algorithm 1 Obtain the location of a spark}

\begin{tabular}{|c|c|}
\hline 1. & Initialize the location of the spark: $\widetilde{x}_{j}=x_{i}$ \\
\hline 2. & $z=\operatorname{round}($ d.rand $(0,1))$ \\
\hline 3. & Select $\tilde{x}_{j}$ of $z$ dimension randomly \\
\hline 4. & Calculate displacement $h=A_{i} \cdot \operatorname{rand}(-1,1)$ \\
\hline 5. & $\begin{array}{l}\text { For each dimension of } \tilde{x}_{k}^{j} \text { (Previously selected } z \text { dimension } \\
\text { of } \widetilde{x}_{j} \text { ) do }\end{array}$ \\
\hline 6. & $\tilde{x_{k}^{j}}=\tilde{x_{k}^{j}}+h$ \\
\hline 7. & If $\tilde{x_{k}^{j}}<x_{k}^{\min }$ or $\left.\tilde{x_{k}^{j}}\right\rangle x_{k}^{\max }$ then \\
\hline 8. & Map $\tilde{x_{k}^{j}}$ to potential space $\tilde{x}_{k}^{j}=x_{k}^{\min }+\left|\tilde{x_{k}^{j}}\right| \%\left(x_{k}^{\max }-x_{k}^{\min }\right)$ \\
\hline 9. & End if \\
\hline 10. & End for \\
\hline
\end{tabular}

Gaussian distribution can be used to maintain diversity in sparks generation. Gaussian expression with a standard deviation and mean of 1 i.e., Gaussian $(1,1)$ is used as shown in Algorithm 2.

Algorithm 2: For obtaining the location of a specific spark

1. Initialize the location of the spark: $\widehat{x_{j}}=x_{i}$

2. $z=\operatorname{round}($ d.rand $(0,1))$

3. Select $\tilde{x}_{j}$ of $z$ dimension randomly

4. Calculate the coefficient of Gaussian explosion: $h=A_{i}$ Gaussian $(1,1)$

5. For each dimension of $\widehat{x_{k}^{j}}$ (Previously selected $z$ dimension of $\left.\widehat{x_{j}}\right)$ do

6. $\widehat{x_{k}^{j}}=\widehat{x_{k}^{j}} \cdot h$

7. If $\widehat{x_{k}^{j}}<x_{k}^{\min }$ or $\widehat{x_{k}^{j}}>x_{k}^{\min }$ then

8. Map $\widehat{x_{k}^{j}}$ to potential space $\widehat{x_{k}^{j}}=x_{k}^{\min }+\left|\widehat{x_{k}^{j}}\right| \%\left(x_{k}^{\max }-x_{k}^{\min }\right)$

9. End if

10. End for

\subsubsection{Location selection}

The current best location $(\mathrm{x} *)$ corresponding to the lowest objective function value and the distance of other $(n-1)$ locations from current best location is used to select the locations for each explosion generation. Usually the two locations $x_{i} x_{j}$ are separated by a distance given by

$R\left(x_{i}\right)=\sum_{j \in K} d\left(x_{i}, x_{j}\right)=\sum_{j \in K}\left\|x_{i}-x_{j}\right\|$

where $K$ corresponds to set of current locations of fireworks and sparks. Thereupon, the probability of selection for location $x_{i}$ is given by

$p\left(x_{i}\right)=\frac{R\left(\mathrm{x}_{\mathrm{i}}\right)}{\sum_{j \in K} R\left(x_{i}\right)}$

Algorithm 3 Heuristic adjustment

1. Check for minimum reserve requirement

2. If ((14) is violated) then

3. Sort all binary 0 bit for one-time interval and Turn-On the unit according to the priority

4. End if

5. Check for minimum up/down time constraints

6. If ((18) is violated) then

7. Turn-on or turn-off units to satisfy the min. up/down time constraints along with respect to the minimum reserve constraint;

8. End if 
Algorithm 4 Heuristic adjustment

1. Initialize all parameters of BFWA and thermal units

2. Select random $n$ locations with dimension $G \times T$ and calculate the objective function value

3. for $i=1$ to MaxItr do

4. Calculate number of sparks using (21)-(22)

5. Calculate amplitude of Explosion using (23)

6. Obtain the location of a spark using Algorithm 1

7. Apply pseudo-random probability transition rule for assigning unit state

8. Carry out heuristic adjustment using Algorithm 3

9. Calculate economic load dispatch (ELD) and fitness

10. Obtain the location of a specific spark using Algorithm 2

11. Apply pseudo-random probability transition rule for assigning unit state

12. Carry out heuristic adjustment using Algorithm 3

13. Calculate ELD and fitness

14. For next iteration sort fitness and select based on current best location

15. Rest of the $(n-1)$ locations is selected using (25)-(26)

16. End for

\subsection{Proposed BFWA for solving UCP}

Before the commitment of thermal units, their ON/OFF status has to be decided. ON/OFF status of each unit is constricted by strict constraints like reserve, load satisfaction and unit's operating characteristics like up/down times, ramp rate limits. Pertaining to such constraint satisfaction, ON/OFF status is adjusted utilizing heuristic adjustment [20]. The heuristic system shows a direct repairing strategy in constraint satisfaction through alteration of ON and OFF conditions of thermal units as indicated by their need in the event of constraint violation, while the indirect systems punish the fitness function value to avoid constraint conflict [21].

Once the ON/OFF states for thermal units are appointed, the assignment of the optimization method is to designate power generation levels of thermal units to minimize the aggregate operational cost. In this methodology firstly, the system with all BFWA and thermal unit parameters is designed. Thereupon, arbitrary locations are chosen for initiation of fireworks explosion using Algorithm 1. After that, based on Algorithm 2, the number of sparks and the amplitude of the sparks are obtained. Thereafter, (25) and (26) are used to calculate the distance of the sparks from current best spark and selection of sparks for the next generation of explosions. The explosion process is terminated when any of the termination criteria is satisfied.

\section{Results and discussion}

The simulations for solving UCP using BGWA are carried out in MATLAB R2012b environment operating on Mac OS X version 10.9 .1 and $2.7 \mathrm{GHz}$ processor. The dimensionality of the problem is considered by increasing the number of generators from 10 to 100 units and corresponding simulation results are evaluated and compared. The test system consists of 10 thermal units whose information is taken from [29] to tackle the UC problem. The generation units are committed and scheduled for a time horizon of 24 hours and for the load taken from [29]. Statistical and surveying methods being the most used ones for this purpose which estimates the availability of EV's in parking lot for $\mathrm{V} 2 \mathrm{G}$ deployment and inferences made from such surveys are considered in aggregating $50000 \mathrm{EV}$ fleets [30]. Limit of PVG and WEC are considered to be $40 \mathrm{MWp}$ and $30 \mathrm{MW}$ respectively and the hourly climate information [31] on average basis is used to simulate the power generation from RETs. Model parameters for wind energy model are $P_{w t r}=2100 \mathrm{~kW}$ (14 identical turbines considered), $V_{c i}, V_{r}, V_{c o}$ are $3.5 \mathrm{~m}, 11 \mathrm{~m}, 20 \mathrm{~m}$ respectively and turbine parameters $\alpha, \beta, \gamma$ are $23,-59,27$ respectively for 2.1 MW turbine considered. Model parameters for SPV are: $\lambda=0.536 \mathrm{w} / \mathrm{m}^{2}$ per ${ }^{\circ} \mathrm{C}$ [27], $P_{m p}=40 \mathrm{MW}$.

In this work, a total of five scenarios are outlined namely: (1) without PEV and RET; (2) with PEV for load leveling; (3) with PEV and wind energy generator (WEG); (4) with PEV and solar photovoltaic generator (SPV); (5) with PEV and hybrid renewable energy technology (HRET).

\section{Case 1: Without PEV and RET}

The first case comprises of the traditional electric network without RET integration and the EV deployment. The cost and emissions in this case are $\$ 579450$ and 21754 tons respectively. The performance comparison and schedule for the traditional scenario is given in Table 1 and Table 2 respectively. The convergence characteristics of cost and emissions for case 1 are shown in Fig. 2.

Case 2: Scheduling scenario with PEV for load levelling

In this scenario, PEV with battery or fuel cell or both of them is scheduled in conjunction with the thermal units. The PEV driving patterns and the frequency of trips information along with the network's forecasted load is used to schedule the PEVs for load levelling application via valley filling mechanism, as shown in Fig. 3.

In this scenario both the cost of scheduling and emissions are increased by $1.61 \%$ and $1.35 \%$ respectively when compared to the base case or the traditional case. The increase in cost and emissions can be attributed to the fact 
Table 1 BFWA performance comparison for fitness value (\$)

\begin{tabular}{|c|c|c|c|c|c|c|}
\hline \multirow[t]{2}{*}{ Algorithm } & \multicolumn{6}{|c|}{ Number of units } \\
\hline & 10 & 20 & 40 & 60 & 80 & 100 \\
\hline LR [15] & 565825 & 1130660 & 2258503 & 3394066 & 4526022 & 5657277 \\
\hline GA [16] & 565825 & 1126243 & 2251911 & 3376625 & 4504933 & 5627437 \\
\hline EP [32] & 564551 & 1125494 & 2249093 & 3371611 & 4498479 & 5623885 \\
\hline MA [33] & 565827 & 1128192 & 2249589 & 3370820 & 4494214 & 5616314 \\
\hline GRASP [34] & 565825 & 1128160 & 2259340 & 3383184 & 4525934 & 5668870 \\
\hline LRPSO [19] & 565869 & 1128072 & 2251116 & 3376407 & 4496717 & 5623607 \\
\hline PSO [10] & 564212 & 1125983 & 2250012 & 3374174 & 4501538 & 5625376 \\
\hline IBPSO [21] & 563977 & 1125216 & 2248581 & 3367865 & 4491083 & 5610293 \\
\hline BFWA & 563977 & 1124858 & 2248228 & 3367445 & 4491284 & 5610954 \\
\hline
\end{tabular}

Table 2 Load dispatch for scheduling scenario without PEV and RET

\begin{tabular}{|c|c|c|c|c|c|c|c|c|c|c|}
\hline Hour & Unit 1 & Unit 2 & Unit 3 & Unit 4 & Unit 5 & Unit 6 & Unit 7 & Unit 8 & Unit 9 & Unit 10 \\
\hline 1 & 245 & 455 & 0 & 0 & 0 & 0 & 0 & 0 & 0 & 0 \\
\hline 2 & 295 & 455 & 0 & 0 & 0 & 0 & 0 & 0 & 0 & 0 \\
\hline 3 & 233 & 455 & 0 & 0 & 162 & 0 & 0 & 0 & 0 & 0 \\
\hline 4 & 333 & 455 & 0 & 0 & 162 & 0 & 0 & 0 & 0 & 0 \\
\hline 5 & 253 & 455 & 130 & 0 & 162 & 0 & 0 & 0 & 0 & 0 \\
\hline 6 & 455 & 223 & 130 & 130 & 162 & 0 & 0 & 0 & 0 & 0 \\
\hline 7 & 273 & 455 & 130 & 130 & 162 & 0 & 0 & 0 & 0 & 0 \\
\hline 8 & 323 & 455 & 130 & 130 & 162 & 0 & 0 & 0 & 0 & 0 \\
\hline 9 & 455 & 258 & 130 & 130 & 162 & 80 & 85 & 0 & 0 & 0 \\
\hline 10 & 455 & 303 & 130 & 130 & 162 & 80 & 85 & 55 & 0 & 0 \\
\hline 11 & 455 & 298 & 130 & 130 & 162 & 80 & 85 & 55 & 55 & 0 \\
\hline 12 & 419.2 & 392.2 & 117.9 & 118.9 & 132.1 & 80 & 74.2 & 55 & 55 & 55 \\
\hline 13 & 455 & 303 & 130 & 130 & 162 & 80 & 85 & 55 & 0 & 0 \\
\hline 14 & 455 & 258 & 130 & 130 & 162 & 80 & 85 & 0 & 0 & 0 \\
\hline 15 & 323 & 455 & 130 & 130 & 162 & 0 & 0 & 0 & 0 & 0 \\
\hline 16 & 455 & 173 & 130 & 130 & 162 & 0 & 0 & 0 & 0 & 0 \\
\hline 17 & 260 & 455 & 130 & 130 & 25 & 0 & 0 & 0 & 0 & 0 \\
\hline 18 & 455 & 223 & 130 & 130 & 162 & 0 & 0 & 0 & 0 & 0 \\
\hline 19 & 158 & 455 & 130 & 130 & 162 & 80 & 85 & 0 & 0 & 0 \\
\hline 20 & 455 & 303 & 130 & 130 & 162 & 80 & 85 & 55 & 0 & 0 \\
\hline 21 & 455 & 258 & 130 & 130 & 162 & 80 & 85 & 0 & 0 & 0 \\
\hline 22 & 455 & 223 & 130 & 130 & 162 & 0 & 0 & 0 & 0 & 0 \\
\hline 23 & 283 & 455 & 0 & 0 & 162 & 0 & 0 & 0 & 0 & 0 \\
\hline 24 & 345 & 455 & 0 & 0 & 0 & 0 & 0 & 0 & 0 & 0 \\
\hline
\end{tabular}

that, the charging load of PEV adds to the generation cost resulted due to increased demand and at the same time driving the generation to maximum levels thereby propelling the quadratic term of the emission function. However, the conversion of conventional fossil fuelled vehicle to green means of transportation, there is a yearly savings of 326678.766 tons [27].
Therefore, the overall equation settles down to a saving of 601 tons per day as the shift in transportation. Also, the constant hike in the oil prices and the reduction in the electricity cost adds to the benefits of the PEV deployment in terms of economic as well as environmental prospects. The convergence characteristics of cost and emissions for case 2 are shown in Fig. 4. 


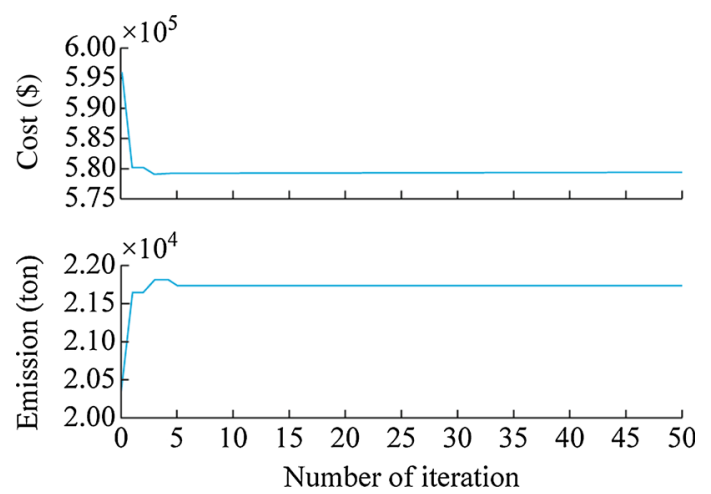

Fig. 2 Dual objectives convergence for case 1

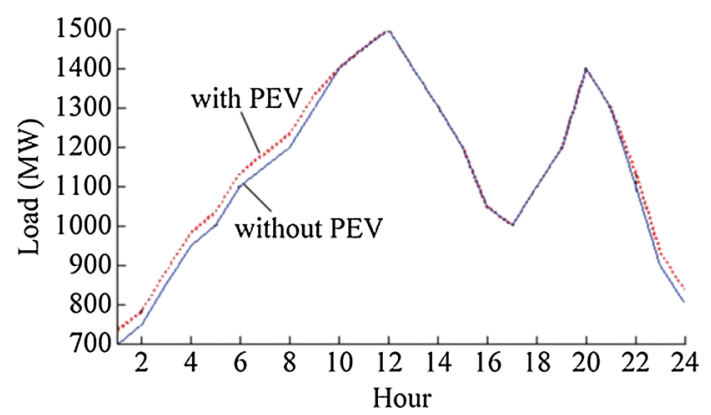

Fig. 3 Load pattern with and without PEV

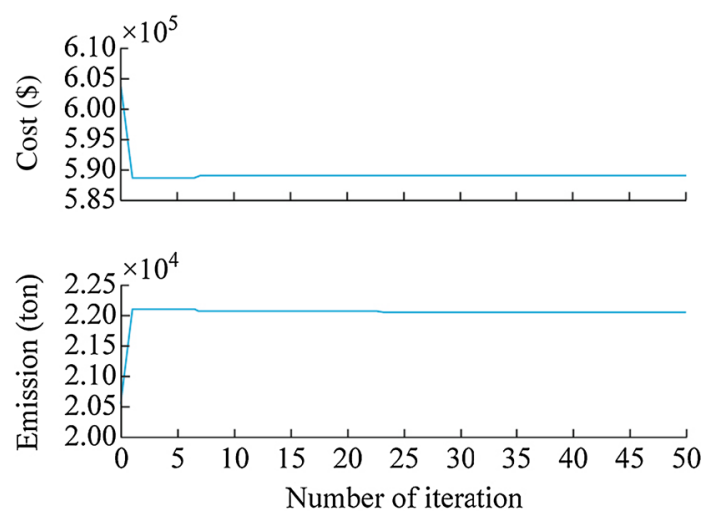

Fig. 4 Dual objectives convergence for case 2

\section{Scheduling in smart grid}

The smart grid models incorporate scheduling of RETs along with the PEV. Three possible scenarios are explored in this work as explained below.

\section{Case 3: Scheduling scenario with PEV and SPV}

In this scenario, both PEV and SPV are scheduled in conjunction with thermal units. The SPV daily generation of 306 MW per day peaking is at 13th hour, as shown in Fig. 5. The coincidence of peak solar generation and peak load resulted in offsetting of peak thermal generation units thereby reducing the cost when compared to case 1 and

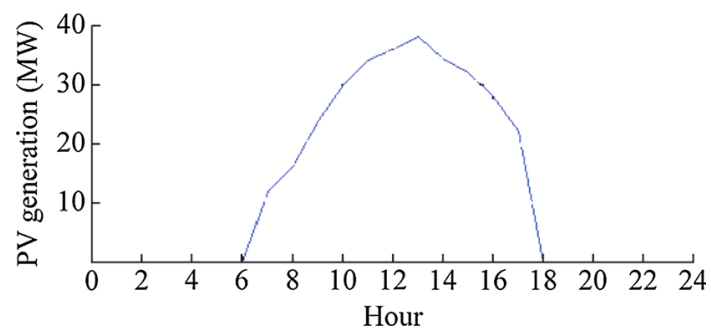

Fig. 5 SPV hourly generation

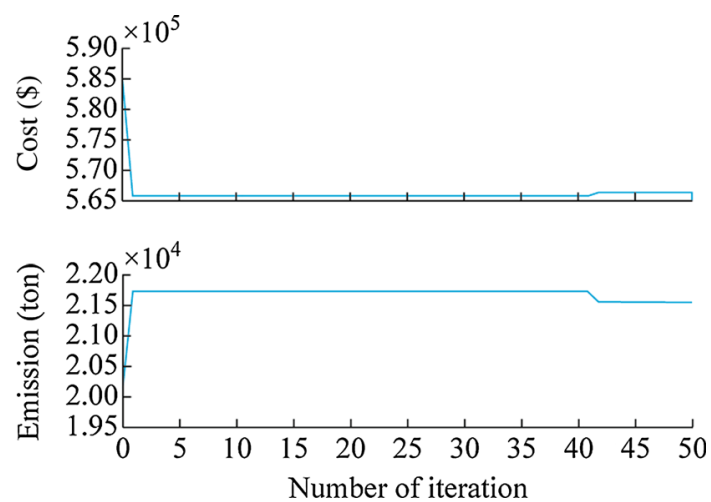

Fig. 6 Dual objectives convergence for case 3

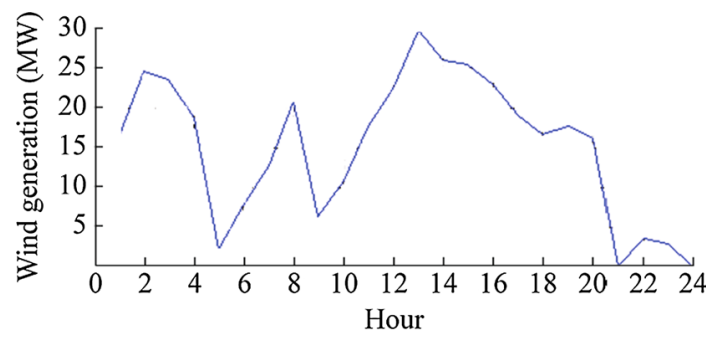

Fig. 7 WEG hourly generation

case 2 . The reduction in cost compared to case 1 and case 2 is \$ 18024.07372 and \$ 23693.2972 respectively.

Also the emissions are reduced by $1.67 \%$ compared to case 2 as the PEV load is now supplied partly from emission-free RET (SPV). The convergence characteristics of cost and emissions for case 3 are shown in Fig. 6.

Case 4: Scheduling scenario with PEV and WEG

This scenario represents PEV scheduling along with a typical wind thermal co-scheduling where, the wind generation aids the thermal power in providing the network and PEV charging load. The wind generation has a peak generation of $30 \mathrm{MW}$ at 12th hour (Fig. 7) and a daily generation of $365.5 \mathrm{MW}$. The cost and emissions are reduced compared to case 1 , case 2 and case 3 by $\$ 18555.47, \$ 24224.69$ and $\$ 531.40$ respectively. The overall reduction in the cost compared to previous three cases is due to the higher generation from WEG compared 


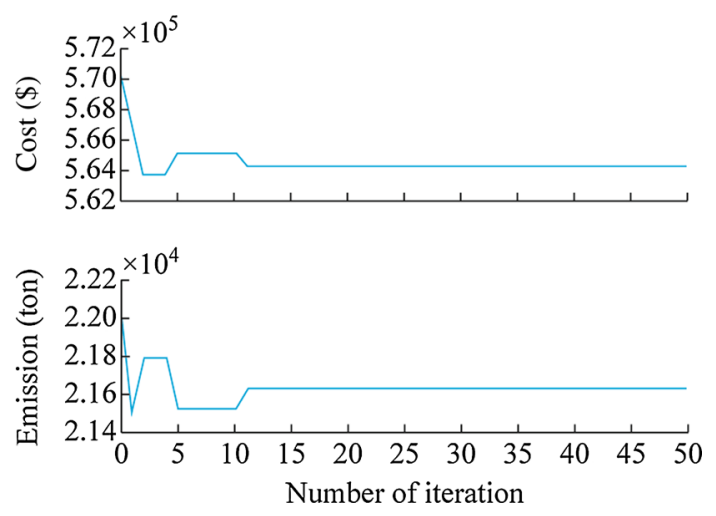

Fig. 8 Dual objectives convergence for case 4

to that from SPV. This case has also resulted in lower emissions compared to case 3 which is due increased generation from the RET (WEG). The convergence characteristics of cost and emissions for case 4 are shown in Fig. 8.

\section{Case 5: Scheduling scenario with PEV and HRET}

This scenario presents a more advanced prospect of the smart grid i.e., incorporation of vehicle to grid (V2G) mode in scheduling scenario (Fig. 9). The convergence characteristics of cost and emissions for case 5 are shown in Fig. 10. The inherent advantage of this scenario is that, the complementary nature of WEG and SPV. The scenario has

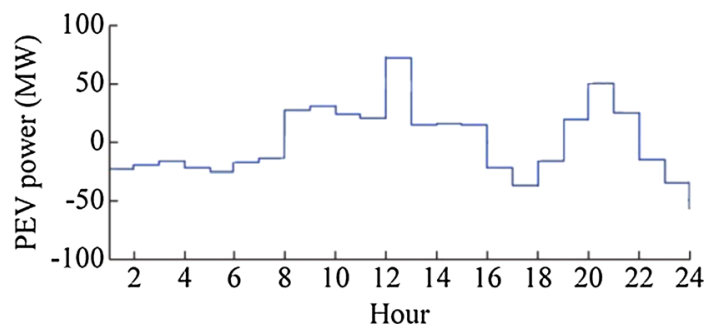

Fig. 9 Charge (-ve value) and discharge (+ve value) pattern of PEV for 24 hours
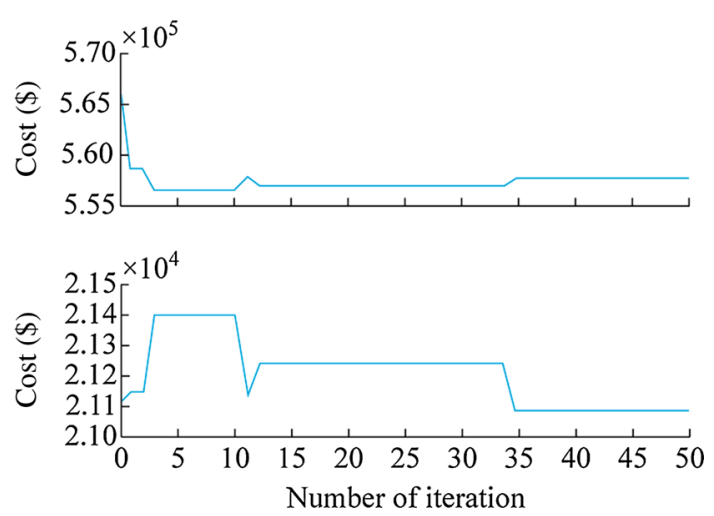

Fig. 10 Dual objectives convergence for case 5

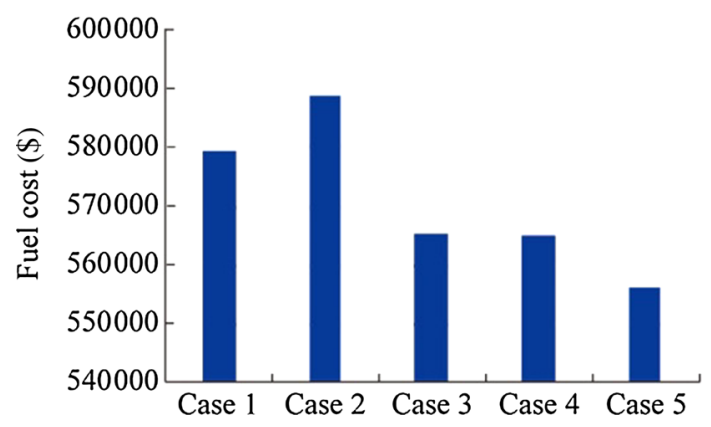

Fig. 11 Cost comparison across different scenarios

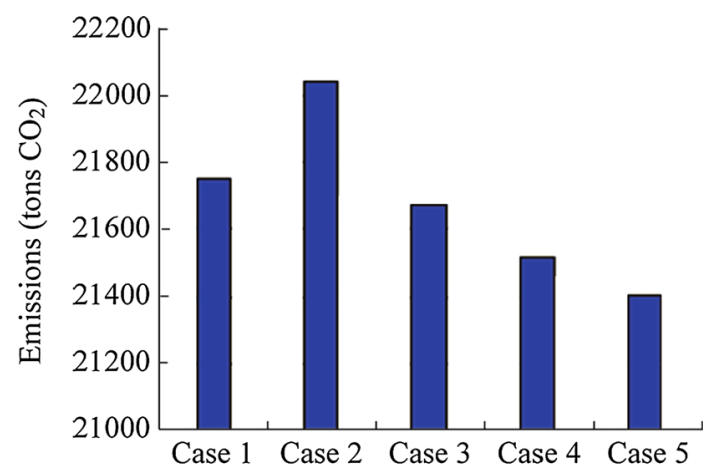

Fig. 12 Emission comparison across different scenarios

resulted in lowest cost (\$556488) and emissions (21400.40305 tons) compared to any other scenario with PEV deployment i.e., case 2 to case 4 (Fig. 11, Fig. 12). It can be observed that, PEV charging is carried out in the off-peak hours and energy stored in battery pack of PEV is utilized at peak hours to levelize the load thereby reducing the fuel cost of the thermal units (Fig. 9). The fuel cat for different scenarios conclude that, effective use of both PEV and HRET can potentially reduce the fuel cost/generation cost for the utility (Fig. 11). The thermal unit generation scheduling for case 5 is shown in Table 3 .

The convergence of cost and emission functions (Fig. 10) is attained at higher number of iterations compared to remaining cases which can be attributed to the increased complexity of system.

\section{Conclusion}

In this paper, an attempt is made to examine the impact of mediation of PEVs and RETs into power system and transportation segments as a piece of modernization of existing network into smart grid. The thermal units are then planned intelligently in conjunction with EVs and RETs accounting both economical as well as environmental viability which are often two mutually exclusive entities to deal with. Then the proposed binary version of fireworks 
Table 3 Load dispatch for scheduling scenario with PEV and HRET

\begin{tabular}{|c|c|c|c|c|c|c|c|c|c|c|}
\hline Hour & Unit 1 & Unit 2 & Unit 3 & Unit 4 & Unit 5 & Unit 6 & Unit 7 & Unit 8 & Unit 9 & Unit 10 \\
\hline 1 & 251.32 & 455 & 0 & 0 & 0 & 0 & 0 & 0 & 0 & 0 \\
\hline 2 & 289.31 & 455 & 0 & 0 & 0 & 0 & 0 & 0 & 0 & 0 \\
\hline 3 & 225.02 & 455 & 0 & 0 & 162 & 0 & 0 & 0 & 0 & 0 \\
\hline 4 & 336.43 & 455 & 0 & 0 & 162 & 0 & 0 & 0 & 0 & 0 \\
\hline 5 & 455 & 276.06 & 130 & 0 & 162 & 0 & 0 & 0 & 0 & 0 \\
\hline 6 & 455 & 232.87 & 130 & 130 & 162 & 0 & 0 & 0 & 0 & 0 \\
\hline 7 & 455 & 262.3 & 130 & 130 & 162 & 0 & 0 & 0 & 0 & 0 \\
\hline 8 & 455 & 257.86 & 130 & 130 & 162 & 0 & 0 & 0 & 0 & 0 \\
\hline 9 & 455 & 455 & 88.57 & 130 & 25 & 0 & 85 & 0 & 0 & 0 \\
\hline 10 & 293.44 & 455 & 130 & 130 & 162 & 80 & 85 & 0 & 0 & 0 \\
\hline 11 & 455 & 280.59 & 130 & 130 & 162 & 80 & 85 & 55 & 0 & 0 \\
\hline 12 & 271.36 & 455 & 130 & 130 & 162 & 80 & 85 & 55 & 0 & 0 \\
\hline 13 & 455 & 455 & 86.97 & 130 & 25 & 80 & 85 & 0 & 0 & 0 \\
\hline 14 & 455 & 260.81 & 130 & 130 & 162 & 0 & 85 & 0 & 0 & 0 \\
\hline 15 & 455 & 250.28 & 130 & 130 & 162 & 0 & 0 & 0 & 0 & 0 \\
\hline 16 & 280.44 & 455 & 130 & 130 & 25 & 0 & 0 & 0 & 0 & 0 \\
\hline 17 & 256.2 & 455 & 130 & 130 & 25 & 0 & 0 & 0 & 0 & 0 \\
\hline 18 & 455 & 222.61 & 130 & 130 & 162 & 0 & 0 & 0 & 0 & 0 \\
\hline 19 & 205.96 & 455 & 130 & 130 & 162 & 80 & 0 & 0 & 0 & 0 \\
\hline 20 & 455 & 321.11 & 130 & 130 & 162 & 80 & 0 & 0 & 55 & 0 \\
\hline 21 & 455 & 318.01 & 130 & 130 & 162 & 80 & 0 & 0 & 0 & 0 \\
\hline 22 & 455 & 235.01 & 130 & 130 & 162 & 0 & 0 & 0 & 0 & 0 \\
\hline 23 & 455 & 185.29 & 0 & 130 & 162 & 0 & 0 & 0 & 0 & 0 \\
\hline 24 & 239.28 & 455 & 0 & 0 & 162 & 0 & 0 & 0 & 0 & 0 \\
\hline
\end{tabular}

algorithm is used to commit and schedule the thermal units along with the PEV and RET efficiently. Five scenarios are laid down of which least cost (best suited option economically) is achieved in case of thermal unit scheduling with PEVs and HRETs which could be credited to the complementary nature of SPV and WEG counterbalancing the costly plants at the peak time while minimum emissions (best suited option environmentally/sustainably) is observed in the scheduling scenario where scheduling is carried out with PEVs and HRETs. The inherent property of fast convergence of the fireworks algorithm has enabled in arriving at optimal tradeoff solution without compromising on the execution time.

Open Access This article is distributed under the terms of the Creative Commons Attribution 4.0 International License (http:// creativecommons.org/licenses/by/4.0/), which permits unrestricted use, distribution, and reproduction in any medium, provided you give appropriate credit to the original author(s) and the source, provide a link to the Creative Commons license, and indicate if changes were made.

\section{References}

[1] Gupta S, Tirpak DA, Burger N et al (2007) Chaptor 13: policies, instruments and co-operative arrangements. In: Metz B,
Davidson OR, Bosch PR et al (eds) Climate change 2007: working group III: mitigation of climate change, IPCC 4th assessment report, intergovernmental panel on climate change (IPCC). Cambridge University Press, Cambridge

[2] Kyoto protocol to the united nation framework convention on climate change. United Nations, New York, NY, USA, 1998

[3] The modern grid initiative. Pacific Northwest National Laboratory, Grid Wise Architecture Council, Richland, WA, USA, 2008

[4] Lu B, Shahidehpour M (2005) Unit commitment with flexible generating units. IEEE Trans Power Syst 20(2):1022-1034

[5] Bu SR, Yu FR, Liu PX (2011) Stochastic unit commitment in smart grid communications. In: Proceedings of the 2011 IEEE conference on computer communications workshops (INFOCOM WKSHPS'11), Shanghai, China, 10-15 Apr 2011, pp 307-312

[6] Khorsand MA, Zakariazadeh A, Jadid S (2011) Stochastic windthermal generation scheduling considering emission reduction: A multiobjective mathematical programming approach. In: Proceedings of the 2011 Asia-Pacific power and energy engineering conference (APPEEC'11), Wuhan, China, 25-28 Mar 2011, pp 25-28

[7] Chakraborty S, Senjyu T, Yona A et al (2009) Fuzzy unit commitment strategy integrated with solar energy system using a modified differential evolution approach. In: Proceedings of the transmission \& distribution conference \& exposition: Asia and Pacific, Seoul, Republic of Korea, 26-30 Oct 2009, pp 26-30

[8] Botterud A, Zhou Z, Wang JH et al (2013) Demand dispatch and probabilistic wind power forecasting in unit commitment and 
economic dispatch: a case study of Illinois. IEEE Trans Sustain Energy 4(1):250-261

[9] Dyke KJ, Schofield N, Barnes M (2010) The impact of transport electrification on electrical networks. IEEE Trans Ind Electron 57(12):3917-3926

[10] Saber AY, Venayagamoorthy GK (2009) Unit commitment with vehicle-to-grid using particle swarm optimization. In: Proceedings of the 2009 IEEE Bucharest PowerTech conference, Bucharest, Romanian, 28 Jun-2 Jul 2009, 8 pp

[11] Khodayar ME, Wu L, Shahidehpour M (2012) Hourly coordination of electric vehicle operation and volatile wind power generation in SCUC. IEEE Trans Smart Grid 3(3):1271-1279

[12] Delarue E, Cattrysse D, D'haeseleera W (2013) Enhanced priority list unit commitment method for power systems with a high share of renewables. Electr Power Syst Res 105(6):115-123

[13] Wang C, Shahidehpour SM (1993) Effects of ramp-rate limits on unit commitment and economic dispatch. IEEE Trans Power Syst 8(3):1341-1350

[14] Viana A, Pedroso JP (2013) A new MILP-based approach for unit commitment in power production planning. Int $\mathrm{J}$ Electr Power Energy Syst 44(1):997-1005

[15] Jiang QY, Zhou BR, Zhang MZ (2013) Parallel augment Lagrangian relaxation method for transient stability constrained unit commitment. IEEE Trans Power Syst 28(2):1140-1148

[16] Kazarlis SA, Bakirtzis AG, Petridis V (1996) A genetic algorithm solution to the unit commitment problem. IEEE Trans Power Syst 11(1):83-92

[17] Cheng CP, Liu CW, Liu CC (2000) Unit commitment by Lagrangian relaxation and genetic algorithms. IEEE Trans Power Syst 15(2):707-714

[18] Zhao B, Guo CX, Bai BR et al (2006) An improved particle swarm optimization algorithm for unit commitment. Int J Electr Power Energy Syst 28(7):482-490

[19] Balci HH, Valenzuela JF (2004) Scheduling electric power generations using particle swarm optimization combined with the Lagrangian relaxation method. Int J Appl Math Comput Sci 14(3):411-421

[20] Panwar LK, Srikanth Reddy K, Kumar R (2014) Productive use of distributed renewable generation source with electric vehicle in smart grid. In: Proceedings of the 6th IEEE power India international conference (PIICON'14), Delhi, India, 5-7 Dec 2014, 6 pp

[21] Yuan XH, Nie H, Su AJ et al (2009) An improved binary particle swarm optimization for unit commitment problem. Expert Syst Appl 36(4):8049-8055

[22] Vaisakh K, Srinivas LR (2011) Evolving ant colony optimization based unit commitment. Appl Soft Comput 11(2):28632870

[23] Tan Y, Zhu YC (2010) Fireworks algorithm for optimization. In: Advances in swarm intelligence: proceedings of the 1st international conference on swarm intelligence (ICSI'10), part 1, Beijing, China, 12-15 Jun 2010, LNCS 6145, pp 355-364

[24] El-Fouly THM, El-Saadany EF, Salama MMA (2006) Grey predictor for wind energy conversion systems output power prediction. IEEE Trans Power Syst 21(3):1450-1452

[25] Chang TP, Liu FJ, Ko HH et al (2014) Comparative analysis on power curve models of wind turbine generator in estimating capacity factor. Energy 73(7):88-95

[26] Rekioua D, Matagne E (2012) Modeling of solar irradiance and cells. In: Rekioua D, Matagne E (eds) Optimization of photovoltaic power systems: modelization, simulation and control. Springer, London, pp 31-37

[27] Osterwald CR, Glatfelter T, Burdick J (1987) Comparison of the temperature coefficients of the basic I-V parameters for various types of solar cells. In: Proceedings of the 19th IEEE photovoltaic specialists conference (PVSC'87), New Orleans, LA, USA, 4 May 1987, pp 188-193

[28] Saber AY, Venayagamoorthy GK (2011) Plug-in vehicles and renewable energy sources for cost and emission reductions. IEEE Trans Ind Electron 58(4):1229-1238

[29] Saber AY, Venayagamoorthy GK (2010) Efficient utilization of renewable energy sources by gridable vehicles in cyber-physical energy systems. IEEE Syst J 4(3):285-294

[30] California plug-in electric vehicle driver survey results. California Center for Sustainable Energy, San Diego, CA, USA, 2013

[31] Gholami A, Jamei M, Ansari J et al (2014) Combined economic and emission dispatch incorporating renewable energy sources and plug-in hybrid electric vehicles. Int J Energy Sci 4(2):60-67

[32] Juste KA, Kita H, Tanaka E et al (1999) An evolutionary programming solution to the unit commitment problem. IEEE Trans Power Syst 14(4):452-459

[33] Valenzuela J, Smith AE (2002) A seeded memetic algorithm for large unit commitment problems. J Heuristics 8(2):173-195

[34] Viana A, Sausa JPD, Matos M (2003) Using GRASP to solve the unit commitment problem. Ann Oper Res 120(1/2/3/4):117-132

K. Srikanth REDDY received his B. Tech. degree in electrical engineering from Jawaharlal Nehtu Technological University, Kakinada (JNTUK), India in 2012 and M. Tech. degree in Renewable Energy from Malaviya National Institute of Technology, Jaipur, India in 2015. He is now working towards his Ph.D. in Electrical Engineering from Indian Institute of Technology Delhi (IITD), India. His research interests include resource scheduling in smart grids, energy storage and electric vehicle applications in power systems, clean technologies, deregulated electricity markets, market settlements with renewable energy penetration, modelling of uncertainty of renewable sources.

Lokesh Kumar PANWAR received his B. Tech. degree in electrical engineering from Rajasthan Technical University (RTU), Rajasthan, India, in 2012 and M. Tech. degree in Renewable Energy from Malaviya National Institute of Technology, Jaipur, India in 2015. His research interests include smart grid, plug-in electric vehicle, optimization, micro-grid, renewable energy systems and optimization of electric vehicle charging under uncertainty subjected to its mobility in electric network and renewable energy scheduling. He also worked on projects related to optimal component sizing in micro and mini grids, energy dispatch in renewable energy penetrated electricity markets.

Rajesh KUMAR received the B.Tech. (Hons.) degree from National Institute of Technology (NIT), Kurukshetra, India, in 1994, the M.E. (Hons.) degree from Malaviya National Institute of Technology (MNIT), Jaipur, India, in 1997, and the Ph.D. degree from the University of Rajasthan, India, in 2005. Since 1995, he has been a Faculty Member in the Department of Electrical Engineering, MNIT, Jaipur, where he is serving as an Associate Professor. He was Post Doctorate Research Fellow in the Department of Electrical and Computer Engineering at the National University of Singapore (NUS), Singapore, from 2009 to 2011. His research interests include theory and practice of intelligent systems, bio and nature inspired algorithms, computational intelligence and applications to power system, electrical machines and drives.

Bijaya Ketan PANIGRAHI received the Ph.D. degree from Sambalpur University, Sambalpur, India. Since 2005, he has been an Associate Professor with the Department of Electrical Engineering, Indian Institute of Technology (IIT) Delhi, New Delhi, India. Prior to 
joining IIT Delhi, he was a Lecturer at the University College of Engineering, Burla, Sambalpur, for 13 years. His current research interests include the study of advance signal processing techniques, computational intelligence algorithms, and their applications to the electrical engineering domain, particularly to the domain of power systems, the development of advanced DSP tools and machine intelligence techniques for power quality studies, protection of power systems, etc. He is involved in the area of application of evolutionary computing techniques (genetic algorithm, particle swarm optimization, clonal algorithm, ant colony optimization, bacterial foraging, harmony search, etc.) to solve the problems related to power system planning, operation, and control. 